\title{
EDUCAÇÃO EM DIREITOS HUMANOS E DEMOCRACIA: \\ HISTÓRIA, TRAJETÓRIAS E DESAFIOS NOS QUINZE ANOS DO PNEDH
}

\author{
ZENAIDE, Maria de Nazaré Tavares ${ }^{1^{*}}$ \\ ${ }^{1}$ Universidade Federal da Paraíba \\ mntzenaide@uol.com.br ${ }^{*}$
}

\section{RESUMO}

Apresenta-se um balanço dos quinze anos de Plano Nacional de Educação em Direitos Humanos no Brasil. Constrói-se a análise a partir da pesquisa bibliográfica e documental, além da observação participante. Reconstrói-se uma linha do tempo da Educação em Direitos Humanos na América Latina e no Brasil de 1993 balanço do processo de formulação e implementação da Política de Educação em Direitos Humanos no Brasil no período da redemocratização. São quinze anos de avanços e dificuldades a serem identificados, reconhecidos e valorizados do Plano Nacional de Educação em Direitos Humanos no Brasil. a 2018. No âmbito nacional, pretende-se construir um

PALAVRAS-CHAVE: Educação em Direitos Humanos. Políticas públicas. Democracia.

EDUCATION ON HUMAN RIGHTS AND DEMOCRACY:

\section{HISTORY, TRAJECTORIES AND CHALLENGES IN THE FIFTEEN YEARS OF THE PNEDH}

\begin{abstract}
It presents a balance of the fifteen years of National Plan of Education in Human Rights in Brazil. The analysis is constructed from the bibliographical and documentary research, besides the participant observation. A time line of Human Rights Education in Latin America and Brazil is reconstructed from 1993 to 2018. At the national level, it is intended to build a balance of the
\end{abstract}

process of formulation and implementation of the Human Rights Education Policy in Brazil in the period redemocratization. There are fifteen years of advances and difficulties to be identified, recognized and valued of the National Plan for Human Rights Education in Brazil.

KEYWORDS: Education in Human Rights. Public policy. Democracy.

\section{EDUCACIÓN EN DERECHOS HUMANOS Y DEMOCRACIA:}

\section{HISTORIA, TRAJETORIAS Y DESAFÍOS EN LOS QUINCE AÑOS DEL PNEDH}

\section{RESUMEN}

Se presenta un balance de los quince años de Plan Nacional de Se presenta un balance de los quince años de Plan Nacional de Educación en Derechos Humanos en Brasil. Se construye el análisis a partir de la investigación bibliográfica y documental, además de la observación participante. Se reconstruye una línea del tiempo de la Educación en Derechos Humanos en América Latina y en pretende construir un balance del proceso de formulación e implementación de la Política de Educación en Derechos Humanos en Brasil en el período de la redemocratización. Son quince años de avances y dificultades a ser identificados, reconocidos $y$ valorizados del Plan Nacional de Educación en Derechos Humanos en Brasil. Brasil de 1993 a 2018. En el ámbito nacional, se

PALABRAS CLAVE: Educación en Derechos Humanos. Políticas públicas. Democracia. 


\section{INTRODUÇÃO}

Uma década e meia de Plano Nacional de Educação em Direitos Humanos (PNEDH) (2003-2018) demandam reflexões sobre o processo de formulação, revisão e implementação desse compromisso histórico construído ao longo do processo de transição, abertura e redemocratização do país. A Educação em e para os Direitos Humanos no Brasil nasce da resistência cultural e política ainda durante os vinte e um anos de ditadura militar - 1964-1985, a exemplo do que define Adorno (2003) como educação para resistência à opressão, quando trata da experiência totalitária em Auschwitz, quando o uso extremo da força inibiu a empatia e a capacidade de raciocínio moral capazes de fomentar a resistência de uma nação contaminada pela ideia de intolerância e genocídio.

Para analisar o processo de formulação e implementação do PNEDH é importante contextualizar os períodos que antecederam a II Conferência Mundial dos Direitos Humanos realizada em Viena (1993), quando pesquisadores e militantes internacionais de direitos humanos conseguiram inserir no plano de ação um eixo específico voltado para a Educação em Direitos Humanos. Em 1994, durante a Conferência Internacional de Educação em Genebra, foi aprovado no âmbito internacional o Plano de Ação Integrado sobre a Educação para a Paz, os Direitos Humanos e a Democracia, ratificado pela Unesco em 1995.

O Brasil teve um papel relevante na Conferência de Viena no processo de mediação dos conflitos, de sistematização e construção do relatório final. Como desdobramento desse processo, a ONU aprovou, em Assembleia Geral, a Resolução no 49/184/1994, quando os paises membros definiram o periodo correspondente entre 10 de janeiro de 1995 e 31 de dezembro de 2004 como a Década da Educação em Direitos Humanos. Buscou-se com esse passo dar centralidade às ações públicas voltadas para "promover, estimular e orientar essas atividades educacionais". Com esse passo no plano internacional, coube aos estados criarem planos, programas, projetos e ações em direitos humanos introduzindo ações educativas no plano formal e não formal em diferentes campos da política pública (direitos humanos, justiça, segurança, educação, cultura e comunicação, saúde mental e outros).

Com o processo de redemocratização de movimentos sociais, não só denunciaram a violência em sua forma estrutural, social e institucional como exigiram do poder público ações 
preventivas. No contexto democrático, a violência confronta-se e anula os ideais democráticos e os direitos fundamentais, demandando ações de combate e enfrentamento à tortura, à violência de gênero, à discriminação étnica e racial, à xenofobia e à intolerância.

A Educação em Direitos Humanos vem em busca desse desafio: reduzir a violência (social e institucional) que tem se demonstrado uma herança histórica e ao mesmo tempo construir valores democráticos. Benevides (1997, p. 12) define como virtudes democráticas: “a) O amor à igualdade e o consequente horror aos privilégios; b) A aceitação da vontade da maioria, porém com constante respeito aos direitos das minorias".

Se uma parte da Educação em e para os Direitos Humanos expressava a resistência à opressão dos familiares e mortos e desaparecidos políticos frente ao estado totalitário, outra parte da Educação em Direitos Humanos advinha dos processos participativos na luta pelos direitos coletivos.

O processo de elaboração da Carta Constitucional Cidadã foi um momento político relevante onde os setores sociais organizados ampliaram e conquistaram os direitos humanos, em sua versão dos direitos civis e políticos e dos direitos sociais, econômicos e culturais, exigindo a partir desse momento um processo de renovação normativa e reformas institucionais.

Só com a ampliação de direitos e a institucionalização do regime democrático é que Pactos e Convenções Internacionais de Direitos Humanos puderam ser ratificados e incorporados às leis brasileiras pela participação de um congresso e um governo legitimamente eleitos. Do reconhecimento nacional dos direitos humanos internacionais o país passou a criar mecanismos nacionais de proteção dos direitos humanos (leis criando conselhos e estatutos, etc.) e uma política de direitos humanos (conselhos, ouvidorias, curadorias, planos e programas voltados para enfrentar as violações e promover o respeito aos direitos humanos).

Em tempos autoritários, a Educação em e para os Direitos Humanos ocorreu como expressão da resistência à opressão através das Comissões de Justiça e Paz (São Paulo e Pernambuco), dos Serviços de Paz e Justiça, dos Centros de Defesa dos Direitos Humanos (Paraíba, Pernambuco e Ceará), do Movimento de Direitos Humanos do Rio Grande do Sul, do Comitê de Defesa dos Direitos Humanos para os Países do Cone Sul (Clamor), dentre outros (VIOLA, 2008). Já com a instalação do Estado Democrático de Direito, a Educação em Direitos Humanos assumiu desdobramentos em planos, programas e diretrizes incidindo nas políticas educacionais. 
A denúncia e a demanda de proteção e defesa são ações centrais na política de direitos humanos, entretanto, a partir da Conferência de Viena (1993), foi dada maior atenção à Educação em Direitos Humanos. O Brasil foi o terceiro país a criar um Programa Nacional de Direitos Humanos (1996) com ações de proteção a vida e de formação de uma cultura de direitos humanos. Se de um lado foi necessário enfrentar a perpetuação da violência institucional (combate à tortura e aos tratamentos desumanos e degradantes) por outro, também foi emergencial enfrentar a violência social com suas formas de manifestação estrutural, física e simbólica.

Diante das desigualdades sociais, o movimento operário demandou mudanças nas relações e condições de trabalho, enquanto diante da violência institucional os familiares de mortos e desaparecidos políticos exigiram o direito à memória e à verdade. No âmbito social, o movimento popular cobrou ações concretas em face da carestia, da alta de política de moradia e da reforma urbana, assim como os movimentos indenitários cobraram ações públicas que reduzissem a violência e a discriminação racial, de gênero e sexual (GOHN, 1995).

Nessa trilha histórica, muitas mentes e corações inventaram experiências não formais de Educação em Direitos Humanos junto aos movimentos sociais (camponeses, bairros populares, mulheres, pessoas com deficiência, crianças e adolescentes, dentre outros). Na América Latina essas experiências mobilizaram oficinas regionais, cursos, simpósios e colóquios formando uma rede latina de Educação em Direitos Humanos (ZENAIDE, 2014).

Congregando várias demandas sociais, a Educação em e para os Direitos Humanos também surge como expressão do reconhecimento da dignidade como princípio fundante dos direitos humanos e do vínculo societário em processo de desrespeito e/ou discriminação; mas surge, também, como ação educativa para construir uma cultura de respeito aos direitos humanos, de formar sujeitos como protagonistas da cidadania (MAGENDZO, 2006).

O Programa Nacional de Direitos Humanos foi importante para desenvolver linhas de ações indicando ao sistema formal de ensino, da área educacional até a área da segurança e administração penitenciária, metas de ações, pautando a introdução de disciplinas e conteúdos de direitos humanos. Entretanto, só no final da década, em 2003 é que foi criado o Comitê Nacional de Educação em Direitos Humanos e a Coordenação Geral de Educação em Direitos Humanos, que no âmbito do Ministério da Justiça se responsabilizaram em articular diversas demandas em Educação em Direitos Humanos com os diferentes campos da política social. 
No processo de elaboração do Plano Nacional de Educação em Direitos Humanos (PNEDH), foram mobilizados setores da sociedade civil, representações dos organismos internacionais e do poder público nacional que participaram da Consulta Nacional que ampliou a versão de 2003 do PNEDH. Se de um lado a educação em ${ }^{1}$ e para ${ }^{2}$ os direitos humanos pode atuar na visibilização das violações para poder entender e prevenir as formas de violências, por outro lado, propõe criar uma cultura universal de respeito aos direitos humanos lidando com as atitudes e mentalidades, a sensibilidade e a razão, a cultura e as possibilidades de novos modos de agir.

A formulação da política de direitos humanos no Brasil vem ocorrendo da relação conflituosa entre o Estado $^{3}$ e a sociedade civil $^{4}$ como parte do ciclo de formulação, edição, implementação e avaliação da política pública ${ }^{5}$. Para tanto, nos referenciamos em Wildavsky (1979, p. 17 apud RUA, 2012, p. 21), quando explica:

[...] o papel da Análise de Política é encontrar problemas onde soluções podem ser tentadas, ou seja, 'o analista deve ser capaz de redefinir problemas de uma forma que torne possível alguma melhoria'. Portanto, a Análise de Política está preocupada tanto com o planejamento como com a política (politics).

Analisaremos os quinze anos de PNEDH situando a reflexão da Educação em e para os Direitos Humanos na agenda pré e pós-Viena, nas resoluções, décadas e planos das Nações Unidas e da Organização dos Estados Americanos, para então, entrar no processo interno de construção nacional do plano e do comitê nacional, das ações e políticas realizadas de 2003 a 2015. Para tanto, utilizamos a pesquisa bibliográfica e documental assim como a observação participante enquanto membro do Comitê Nacional de Educação em Direitos Humanos.

1 Para Artal (2004, p. 207), a Educação em Direitos Humanos envolve uma educação em um clima de respeito aos direitos humanos; trata da "vía curricular, extracurricular - así como con el currículum oculto - y mediante el ethos y la organización de las escuelas y la sociedad".

2 Para Artal (2004, p. 185), a Educação para os Direitos Humanos envolve "Ia aquisición de las competencias necesarias para el respeto, defensa, promoción e ejercicio responsable de los derechos humanos".

3 Concebemos Estado como relação, mediada por instituições complexas, públicas e privadas, articuladas e em disputas por hegemonia, pois, se de um lado e ao mesmo tempo, o Estado atua para "fortalecer a capacidade produtiva nos setores de maior prioridade para o desenvolvimento", também atua na direção da regulação das tensões sócias e da "responsabilidade da diminuição das desigualdades sociais sob a pressão da sociedade" (IGLESIAS, 2010, p. 50).

4 Adotaremos o conceito de sociedade de Rua (2012, p. 12): "Sociedade é um conjunto de indivíduos, dotados de interesses e recursos de poder diferenciados, que interagem continuamente a fim de satisfazer às suas necessidades".

5 Rua (2012, p. 17) define políticas públicas (policy) como: "resultantes da atividade política (politics): compreendem o conjunto das decisões e ações relativas à alocação imperativa de valores envolvendo bens públicos".

Educação \& Formação, Fortaleza, v. 3, n. 7, p. 137-161, jan./abr. 2018

DOI: http://dx.doi.org/

http://seer.uece.br/redufor 
Esperamos, ao longo do texto, identificar os direitos humanos como expressão de problemas sociais; a estruturação e formulação de temas dos direitos humanos na agenda pública; os processos públicos de tomada de decisões e de implementação de políticas de Educação em Direitos Humanos, encerrando com uma síntese dos avanços e desafios.

\section{A EDUCAÇÃO EM DIREITOS HUMANOS NA AGENDA QUE ANTECEDE VIENA (1993)}

Antes da II Conferência Mundial de Direitos Humanos, em Viena (1993), a Educação em e para os Direitos Humanos na América Latina e Brasil foi sendo gestada concomitantemente às lutas por direitos econômicos, sociais e culturais e pelos direitos civis e políticos com os processos de reconhecimento e formulação dos direitos humanos.

Diante de violações contra a dignidade humana, a Educação em e para os Direitos Humanos passou a ser incorporada em Cartas, Declarações e Convenções como princípio e parâmetro ético da proteção dos direitos. É princípio da Carta das Nações Unidas (1945): “Desenvolver relações amistosas entre as nações, baseadas no respeito ao princípio de igualdade de direitos e de autodeterminação dos povos, e tomar outras medidas apropriadas ao fortalecimento da paz universal". Outro aspecto teórico a ser considerado, a Educação em e para os Direitos Humanos é também parte do direito à educação na Carta da OEA. A educação dos povos deve orientar-se para a justiça, a liberdade e a paz e na Declaração Universal dos Direitos Humanos (1948), "a compreensão comum desses direitos e liberdades é da mais alta importância para o pleno cumprimento desse compromisso". Afirma o artigo 26ㅇ da Carta:

\footnotetext{
1. Todo ser humano tem direito à instrução. A instrução será gratuita, pelo menos nos graus elementares e fundamentais. A instrução elementar será obrigatória. A instrução técnico-profissional será acessível a todos, bem como a instrução superior, está baseada no mérito. 2. A instrução será orientada no sentido do pleno desenvolvimento da personalidade humana e do fortalecimento do respeito pelos direitos humanos e pelas liberdades fundamentais. A instrução promoverá a compreensão, a tolerância e a amizade entre todas as nações e grupos raciais ou religiosos, e coadjuvará as atividades das Nações Unidas em prol da manutenção da paz.
}

Se nas Declarações de direitos iniciadas ao longo das revoluções e declarações burguesas (Declaração de Direitos - Bill Rights, 1689; Declaração de Independência dos Estados Unidos, 1776; Declaração dos Direitos do Homem e do Cidadão, 1789) a Educação em e para os Direitos Humanos 
era vista como parte da constituição do cidadão, a partir do século $X X$, com a Constituição de Weimar em 1919 e a Constituição mexicana de 1917, a diversidade e a igualdade ampliaram a noção de direitos humanos incorporando os direitos coletivos. Com os movimentos identitários, os direitos culturais também passaram a compor a noção contemporâea de direitos humanos.

Desde 1919, com a criação das Ligas das Nações adentrando a década de 1940 com a Organização das Nações Unidas (ONU) e a Organização dos Estados Americanos (OEA), que os crimes contra a humanidade, envolvendo o genocídio, o desaparecimento forçado, as execuções sumárias e a questão dos refugiados que emergem diante da economia e da cultura de guerra. Educar para não repetição requer reconhecer o genocídio, a barbárie e a questão dos refugiados como preocupação dos povos, daí a necessidade da criação de um conjunto de instrumentos como: a Convenção sobre Direito de Asilo - 1928; a Convenção relativa ao Tratamento de Prisioneiros de Guerra - 1929; a Convenção sobre Asilo Político, 1933; a Convenção para a Prevenção e Repressão do Crime de Genocídio, 1948; as Convenções de Genebra I, II, III e IV, 1949; a Convenção Relativa ao Estatuto dos Refugiados, 1951; a Convenção suplementar sobre abolição da escravatura, do tráfico de escravos, e instituições e práticas similares à escravidão, 1956; a Convenção $n^{\circ} 105$ da OIT concernente à abolição do trabalho forçado, 1957; o Protocolo Relativo ao Estatuto dos Refugiados, 1967; a Convenção sobre a Imprescritibilidade de Crimes de Guerra e de Crimes de Lesa-Humanidade, 1968; a Declaração sobre o fomento à juventude dos ideais de paz, respeito mútuo e compreensão dos povos, 1965; a Declaração sobre o direito dos Povos a Paz, 1984; a Convenção Interamericana sobre o Desaparecimento Forçado de Pessoas, 1994 e o Estatuto de Roma do Tribunal Penal Internacional, 1998.

Nesse complexo contexto emergem também as Convenções relevantes ao crime histórico herdado do colonialismo, como a cotinuidade da escravidão estrutural e suas formas correlatas, expandindo para o racismo e a xenofobia, exigindo da humanidade, instrumentos, tais como: Convenção de Genebra sobre a Escravatura - 1926; a Convenção no 29 da OIT relativo a trabalhos forçados, 1930; a Convenção suplementar sobre abolição da escravatura, do tráfico de escravos, e instituições e práticas similares à escravidão, 1956; a Convenção n. 105 da OIT concernente à abolição do trabalho forçado, 1957; a Convenção sobre a Eliminação de todas das formas de Discriminação Racial, 1965; e a Declaração contra o Racismo, a Discriminação Racial, a Xenofobia e Formas Correlatas de Intolerância, 2001.

Educação \& Formação, Fortaleza, v. 3, n. 7, p. 137-161, jan./abr. 2018 
A década de 1940 foi um marco contemporano da humanidade, uma vez que nela foram criadas e aprovadas as princiais Cartas e Declarações da ONU e da Organização dos Estados Americanos (OEA), criando um sistema internacional de proteção dos direitos humanos, como: a Carta das Nações Unidas em 1945, a Carta da Organização dos Estados Americanos, a Declaração Americana dos Direitos e Deveres do Homem, a Declaração Universal dos Direitos Humanos. No Preâmbulo da Declaração Universal dos Direitos Humanos (1948) as Nações Unidas formulam os princípios da Educação em e para os Direitos Humanos pautada na necessidade: do reconhecimento e proteção da dignidade; da resistência à opressão e à violência; da observância dos direitos e das liberdades perante a lei; da igualdade do cidadão; do respeito, à convivência de uma cultura de paz entre os povos.

No plano dos direitos econômicos, sociais e culturais, ainda entre 1948 e 1949 continua a preocupação com as violações aos direitos no mundo do trabalho e das mulheres. Aparece, então, a Convenção no 87 da OIT concernente à liberdade de associação e proteção ao direito sindical em 1948; a Convenção no 98 da OIT concernente à aplicação de princípios do direito de organização e negociação coletiva em 1949; a Convenção no 111 da OIT concernente à discriminação em relação ao emprego ou ocupação, 1958; a Convenção Internacional sobre a Proteção dos Direitos de Todos os Trabalhadores Migrantes e dos Membros das suas Famílias, 1990; a Convenção Interamericana sobre Tráfico Internacional de Menores, 1994; a Convenção 182 da OIT sobre a Proibição e a Ação imediata para a Eliminação das Piores Formas de Trabalho Infantil, 1999; e o Protocolo Facultativo à Convenção sobre os Direitos das Crianças, a Prostituição Infantil e a Pornografia Infantil, 2000.

A questão indígena, embora tenha sido um problema do colonialismo, só recebe atenção do sistema global de proteção dos direitos humanos com a Convenção no 169 da OIT sobre Povos Indígenas e Tribais, 1989, e com a Declaração sobre os Direitos das pessoas pertencentes a minorias nacionais ou étnicas, religiosas e linguísticas, 1992.

No tocante à diversidade humana as mulheres conquistam a Convenção Interamericana sobre a concessão de direitos políticos à Mulher, 1948; a Convenção para a supressão do tráfico de pessoas e da exploração da prostituição de outros, em 1949; a Convenção no 100 da OIT concernente à remuneração igual para homens e mulheres em trabalho de igual valor, 1951, e a Convenção sobre os Direitos Políticos das Mulheres, 1952; Convenção no 122 da OIT concernente à política de emprego, 1964; além da Convenção sobre a Eliminação de Todas as Formas de 
Discriminação contra a Mulher, 1979, e da Convenção Interamericana para Prevenir, Punir e Erradicar a Violência contra a Mulher, 1994. Como desdobramento, a identidade de gênero e sexual tem pautado a criação dos Princípios de Yogyakarta - Princípios sobre a aplicação da legislação internacional de direitos humanos em relação à orientação sexual e identidade de gênero, 2006; a Resolução “Direitos Humanos, Orientação Sexual e Identidade de Gênero", 2008, apresentada pelo Brasil à OEA.

Só apenas nas décadas de 1960 e 1970, aparecem declarações e convenções específicas tratando da violência étnico-racial e de gênero, alertando para o problema da discriminação como fator de desigualdade. Surge, então, a Convenção relativa à luta contra as discriminações na esfera do Ensino, 1960, sendo seguida da Recomendação sobre a Educação para a compreensão, a Cooperação e a Paz Internacional e a Educação relativa aos Direitos Humanos e as Liberdades Fundamentais, 1974; a Declaração de Princípios fundamentais relativos a contribuição dos Meios de Comunicação de Massas para o fortalecimento da paz e da compreensão Internacional à promoção dos direitos humanos e à luta contra o Racismo e o Apartheid e à incitação à Guerra, 1978.

Os direitos humanos relacionados à função coercitiva do Estado tem demandado ainda a criação de instrumentos educativos para orientar a formação na área, como o Código de Conduta para Funcionários encarregados de fazer cumprir a Lei, 1979; Regras Mínimas das Nações Unidas para a Administração da Justiça da Infância e da Juventude - Regra de Beijing, 1985; o Conjunto de Princípios para a Proteção de Todas as Pessoas submetidas a qualquer forma de Detenção ou Prisão, 1988; e os Princípios relativos a uma eficaz prevenção e investigação das execuções extralegais, arbitrárias e sumárias, 1989. No campo da proteção e defesa dos abusos e torturas, emergem a Convenção contra a Tortura e Outros Tratamentos Cruéis, Desumanos e Degradantes, 1984; a Convenção Interamericana para Prevenir e Punir a Tortura, 1985; e o Protocolo Adicional à Convenção Americana sobre Direitos Humanos referente à Abolição da Pena de Morte, 1990.

No âmbito da OEA, a Convenção Americana sobre Direitos Humanos (Pacto de São José da Costa Rica), 1969, ao mesmo tempo em que entende necessária a proibição das formas de escravidão e servidão como resquícios do colonialismo, propõem como parte da Educação em e para os Direitos Humanos, o direito à liberdade e à segurança pessoais, o respeito aos direitos humanos, à integridade pessoal, à liberdade pessoal, de consciência e de religião, de pensamento e de expressão, assim como os direitos políticos. 
Os Pactos dos Direitos Civis e Políticos e dos Direitos Econômicos, Sociais e Culturais, ambos de 1966, destacam o dever dos Estados em promover o respeito universal e efetivo dos direitos e das liberdades do homem.

A diversidade de crenças e religião tem também demandado a criação da Declaração sobre a Eliminação de Todas as Formas de Intolerância e Discriminação fundadas na Religião ou Convicções, 1981; a Declaração de Princípios sobre a Tolerância e o Plano de Ação de Seguimento do Ano das Nações Unidas, 1995.

A questão ambiental aparece como preocupação do processo de crescimento econômico sem sustentabilidade ambiental. Emerge, nesse sentido, a Convenção sobre a Diversidade Biológica, 1992, com a Conferência das Nações Unidas sobre Meio Ambiente e Desenvolvimento - Eco 92, e o Protocolo de Kyoto, da Convenção Marco das Nações Unidas sobre a Mudança Climática, 1997.

Começa em 1974 a iniciativa da Unesco em prestar cooperação internacional aos Estados-Parte sobre a Educação relativa aos direitos humanos, às liberdades e a paz. Após a Convenção contra a Discriminação no Ensino

Na Convenção sobre os Direitos da Criança (1989), o artigo 28o afirma: "1 - Os Estados Partes reconhecem o direito da criança à educação e, a fim de que ela possa exercer progressivamente e em igualdade de condições esse direito, deverão especialmente". Afirma ainda:

\footnotetext{
3 - Os Estados Partes promoverão e estimularão a cooperação internacional em questões relativas à educação, especialmente visando contribuir para a eliminação da ignorância e do analfabetismo no mundo e facilitar o acesso aos conhecimentos científicos e técnicos e aos métodos modernos de ensino. A esse respeito, será dada atenção especial às necessidades dos países em desenvolvimento. (VILHENA, 2001, p. 136).
}

Só em 1974, vinte quatro anos depois da DUDH, que surge uma Recomendação sobre a Educação para a compreensão, a Cooperação e a Paz Internacional e a Educação relativa aos Direitos Humanos e as Liberdades Fundamentais aprovada pela Unesco.

O Brasil, nos anos setenta, vivia as lutas por anistia política. Foi nesse contexto de autoritarismo que surgiram os Centros de Defesa dos Direitos Humanos, as Pastorais Sociais e as Comissões de Justiça e Paz, articuladas à Teologia da Libertação, foi assim na Paraíba em 1976 e em São Paulo em 1979.

Educação \& Formação, Fortaleza, v. 3, n. 7, p. 137-161, jan./abr. 2018

DOI: http://dx.doi.org/ 
A década de 1980 é um marco histórico no Brasil, pois foi nela que os atores sociais enquanto forças lutaram contra o autoritarismo e o regime militar, pelos direitos de moradia, reforma urbana, saúde coletiva, educação e participação social. A educação popular nesse contexto foi importante para o processo de redemocratização. Para Zenaide (2010a, p. 360):

\begin{abstract}
Educação popular é uma prática voltada para distintos coletivos especificamente populares, claramente identificada com a democracia e a justiça social, politicamente engajada com processos de libertação e emancipação do social. A relação entre educação popular e direitos humanos tem sido historicamente tecida ao longo da trajetória histórica dos direitos humanos na contemporaneidade. 0 presente trabalho pretende demonstrar essa relação.
\end{abstract}

As experiências de educação popular situam como um campo de práticas essencialmente políticas, compromissadas com a perspectiva transformadora da sociedade na perspectiva da conquista de direitos de cidadania e o respeito aos direitos humanos. Daí porque a perspectiva crítica da Educação em e para os Direitos Humanos encontram na educação popular princípios fundamentais, como afirma Beto (1998): a relação indissociável entre leitura de mundo e problematização dos conteúdos; reconhecimento das pessoas como sujeitos de dignidade e direitos, a experiência pessoal e social como ponto de partida e chegada, a aproximação da escola com a sociedade e as forças coletivas, a dimensão eminentemente política e amorosa da educação, o acesso à aquisição da linguagem, do ensino da escrita e da leitura como exercício do direito à educação, o diálogo como substrato da democracia e da educação.

Basombrio confirma o caráter jovem da Educação em e para os Direitos Humanos na América Latina e Brasil. Afirma o autor:

\begin{abstract}
A educação em direitos humanos na América Latina é uma prática jovem. Espaço de encontro entre educadores populares e militantes de direitos humanos começa a se desenvolver coincidentemente com o fim de um dos piores momentos da repressão política na América latina e conquista certo nível de sistematização na segunda metade da década e dos 80. [...] A educação em DH é uma prática que tem sido implementada de forma desigual, segundo diferentes realidades nacionais, respondendo, no essencial, a capacidade de ação de entidades ligadas à educação popular e de organizações não governamentais ligadas aos direitos humanos, que tiveram grande importância na luta contra regimes autoritários instalados entre as décadas de 1960 e 1970. (BASOMBRIO apud SILVA, 1995, p. 63).
\end{abstract}

Candau contextualiza a Educação em Direitos Humanos a partir da década de 1980, quando militantes e educadores latino-americanos começaram a construir trajetórias diversas em defesa e

Educação \& Formação, Fortaleza, v. 3, n. 7, p. 137-161, jan./abr. 2018

DOI: http://dx.doi.org/

http://seer.uece.br/redufor 
promoção dos direitos humanos através de experiências educativas não formais vinculadas às lutas de resistência política e de redemocratização (CANDAU apud NOVAMÉRICA, 1998).

\section{A EDUCAÇÃO EM DIREITOS HUMANOS NA AGENDA PÚBLICA PÓS-VIENA}

Durante a II Conferência Mundial de Direitos Humanos, em 1993, realizada em Viena, a Educação em Direitos Humanos é posta como eixo da política de direitos humanos, inserindo no item 81 a necessidade de "programas e estratégias visando especificamente a ampliar ao máximo a Educação em Direitos Humanos e a divulgação de informações públicas nessa área, enfatizando particularmente os direitos humanos da mulher". Já no item 82, propõe o Plano "promover uma maior conscientização dos direitos humanos e da tolerância mútua", assim como "divulgar informações públicas de direitos humanos como forma de intensificar a Campanha Mundial de Informação Pública sobre Direitos Humanos lançada pelas Nações Unidas" (ONU, 1993).

Educadores reunidos na Conferência Internacional de Educação, em Genebra, em 1993, protagonizaram a formulação de um Plano de Ação Integrado sobre a Educação para a Paz, os Direitos Humanos e a Democracia, que foi aprovado pela Conferência Geral da Unesco, em 1995. Ainda no mesmo ano, a Assembleia Geral da Organização das Nações Unidas (ONU), através da Resolução no 49/184, promulgou a Década da Educação em Direitos Humanos, equivalendo ao período de 1o de janeiro de 1995 a 31 de dezembro de 2004, como forma de sensibilizar e mobilizar os Estados a assmirem o compromisso de dar centralidade ao ensino formal. Em seguida, um Plano de Ação para o Decênio das Nações Unidas para a Educação na Esfera dos Direitos Humanos. Só em 2011 é que as Nações Unidas aprovam a Declaração das Nações Unidas sobre Educação e Formação em Matéria de Direitos Humanos.

No âmbito da América Latina, em 1988, o Protocolo Adicional à Convenção Americana sobre Direitos Humanos em Matéria de Direitos Econômicos, Sociais e Culturais (Protocolo de San Salvador), determina conteúdos essenciais que devem orientar a educação em cada um dos Estados Partes, sendo um desses conteúdos o respeito dos direitos humanos.

Na Primeira Cúpula das Américas, realizada em Miami, em 1994, “os governos desenvolveram programas para a promoção e observância dos direitos humanos, inclusive programas educativos que informem a população sobre seus direitos legais e sobre sua obrigação

Educação \& Formação, Fortaleza, v. 3, n. 7, p. 137-161, jan./abr. 2018

DOI: http://dx.doi.org/

http://seer.uece.br/redufor 
de respeitar os direitos de outros". Em 1997, foi realizada a VII Cimeira Ibero-Americana tendo como tema "Os Valores Éticos da Democracia": em 1998, foi aprovado o Programa de Educação para a Paz no Hemisfério.

Em 2001, foi aprovada a Declaração do México sobre Educação em Direitos Humanos durante a Conferência Regional sobre Educação em Direitos Humanos na América Latina. O Plano Latino-Americano para a Promoção da Educação em Direitos Humanos foi aprovado em 2001, durante o Seminário Latino-Americano de Educação para a paz e os Direitos Humanos, na Venezuela. A Carta Democrática Interamericana de 2001, afirma que "a promoção e observância dos direitos econômicos, sociais e culturais são inerentes ao desenvolvimento integral, ao crescimento econômico com equidade e à consolidação da democracia dos Estados do Hemisfério".

Em 2008, foi aprovada pela OEA a Resolução 2404 e em 2009, a Resolução no 2.466, que tratam da Educação em Direitos Humanos na Educação Formal nas Américas. Em 2009, a Resolução no 2.481 aprova o Programa Interamericano sobre Educação em Valores e Práticas Democráticas. Em 2010, através da Resolução no 2.571, é aprovado o Programa Interamericano sobre Educação em Valores e Práticas Democráticas. Em 2010, é ainda aprovado o Pacto Interamericano de Educação em Direitos Humanos. No mesmo ano, é aprovada através da Resolução no 2.604, "A Educação em Direitos Humanos na Educação Formal nas Américas".

As Resoluções 2673 (XLI-O/11) de 2011 e 2732 (XLII-O/12) de 2012 da OEA tratam da Educação em Direitos Humanos na educação formal nas Américas. Já em 2013, a OEA aprovou a AG/DEC. 71, destacando a necessidade dos Estados de promoverem políticas públicas de direitos humanos na educação formal, conforme recomendações do Instituto Interamericano de Educação em Direitos Humanos através dos Informes (2002-2011).

\section{O PNEDH: QUINZE ANOS EM CONSTRUÇÃO E IMPLEMENTAÇÃO}

Para que se possa entender o processo político de elaboração do Plano Nacional de Educação em Direitos Humanos nesses quinze anos, tentaremos recompor momentos distintos da construção. Rua (2012, p. 36) conceitua o ciclo de políticas como: 
conduz os estudiosos a examinar como as decisões são ou poderiam ser tomadas e permite identificar e analisar os processos político administrativos, os mecanismos e estratégias definidas para a realização da política, e o comportamento dos diferentes atores envolvidos em cada etapa do processo de produção de políticas. O ciclo de políticas é uma abordagem para o estudo das políticas públicas que identifica fases sequenciais e interativas-iterativas no processo de produção de uma política.

Abordaremos os quinze anos do PNEDH a partir dos processos de formulação, implementação e avaliação.

\subsection{0 processo de formulação}

Algumas questões orientam o processo de formulação do PNEDH: Quem foram os formuladores do PNEDH? Quais os passos dados na elaboração do PNEDH? Quais os grupos sociais e os setores públicos mobilizados? Como foi o processo de formulação e as instancias de decisões?

O primeiro Ministro de Direitos Humanos, Nilmário Miranda, participante da Conferência de Viena em 1993, convocou assessores técnicos e políticos para levantar nomes de pessoas e instituições com experiências em Educação em Direitos Humanos junto aos movimentos sociais, universidades, órgãos de cooperação internacional e ministérios para comporem o Comitê Nacional de Educação em Direitos Humanos. Nessa articulação dialogou com o Ministério da Justiça, o Ministério da Educação, principais interlocutores governamentais, com o Parlamento através da Comissão de Direitos Humanos e Minorias Sociais e a presidente emérita da Rede Brasileira de Educação em Direitos Humanos, Margarida Genevois, que em 1997, realizou o I Congresso Brasileiro de Educação em Direitos Humanos, em São Paulo.

Atendendo a recomendação da Década da ONU para a Educação em Direitos Humanos (1995-2003), Nilmário Miranda institui a Portaria no 98/2003, criando conforme Diretrizes da ONU o Comitê de âmbito nacional para assessorar a SEDH na construção e monitoramento do PNEDH. Na primeira composição do CNEDH, foram convidados como especialistas em educação em e para os direitos humanos: Aida Maria onteiro (UFPE), Sólon Viola (Unisinos), Maria de Nazaré Tavares Zenaide (UFPB), Maria Vistoria Benevides (USP), Nair Heloisa Bicalho de Sousa (UNB), José Antônio Peres Gediel (UFPR), Vera Maria Candau (PUC/RJ) (BRASIL, 2003). Como representantes governamentais: Ricardo Manuel dos Santos Henriques - MEC; Eliane dos Santos Cavalleiro - MEC; Alayde Freire Sant'anna - MEC; Ivone Moreyra - MEC; Lúcia Helena Lodi - 
MEC; Valéria Sperandio Rangel - MEC; Alberto Albino dos Santos - SEDH; Herbert Borges Paes de Barros - SEDH; Izabel Maria Madeira de Loureiro Maior - SEDH e Perly Cipriano - SEDH. Como representante da Câmara dos Deputados, Márcio Marques de Araújo - CDHM.

Como representantes da sociedade civil: Herilda Balduíno de Souza - OAB; Iradj Roberto Eghrari - Comunidade Baha'i; João Jesus de Salles Pupo - Associação Brasileira de Educação; Margarida Bulhões Pedreira Genevois - Rede Brasileira de Educação em Direitos Humanos; Paulo César Carbonari - Movimento Nacional de Direitos Humanos; Ricardo Brisolla Balestreri - Capec; Roberto de Oliveira Monte - DHNET. A representação da Unesco/Brasil esteve com Carlos Alberto dos Santos Vieira.

Em 2008, o CNEDH foi ampliado através da segunda Portaria 83/2008, com a participação da Associação Nacional de Direitos Humanos, Ensino e Pesquisa (ANDHEP), da Confederação Nacional dos Trabalhadores da Educação (CNTE), do Fórum Nacional pela Democratização dos Meios de Comunicação (FNDC), da Associação Brasileira de Educação (ABE), do Movimento Nacional de Direitos Humanos (MNDH) e da Associação Brasileira de Organizações Não Governamentais (Abong). Com relação aos órgãos públicos federais, participam do CNEDH: a Secretaria Especial dos Direitos Humanos, o Ministério da Educação, o Ministério da Cultura, a Secretaria de Comunicação da presidência da República, o Ministério da Justiça, a Comissão de Direitos Humanos e Legislação Participativa da Câmara Federal e do Senado Federal (BRASIL, 2008).

O Comitê teve como ação inicial a elaboração de uma Minuta para o Plano Nacional de Educação em Direitos Humanos que foi discutida no âmbito nacional através da consulta pública realizada em todos os estados com exceção do Mato Grosso, ação realizada entre a SEDH, o MEC, as Comissões de Direitos Humanos das Assembleias Legislativas e Universidades.Os passos para a elaboração do PNEDH envolveu: a) elaboração da versão preliminar em 2003, que foi objeto de consulta nacional através de vinte e um encontros estaduais de Educação em Direitos Humanos realizados nos Estados da Federação, com o apoio da Comissão de Direitos Humanos e Minorias Sociais da Câmara dos Deputados, de Conselhos Estaduais de Direitos Humanos, Secretarias Estaduais de Justiça e Direitos Humanos, Instituições de Ensino Superior e Entidades de Direitos Humanos.

Após a realização dos Encontros Estaduais foi realizado no Rio de Janeiro, em 2005, um Seminário com o Comitê Nacional de Educação em Direitos Humanos e a Escola de Serviço Social 
que exerceu a consultoria técnica para apresentação e discussão da sistematização dos resultados dos encontros estaduais. Após a entrega à SEDH do trabalho final da consultoria, o CNEDH realizou reunião extraordinária para aprovar o texto final do PNEDH.

No período que antecedeu a realização do Congresso Ibero-Americano de Educação em Direitos Humanos em Brasília, o Ministro dos Direitos Humanos em 2007, Paulo Vannchi, reabriu um período de consulta on line para continuidade do período de sugestões ao PNEDH, assim como solicitou contrinuições aos órgãos do Governo Federal, de modo a encerrar a fase de elaboração do plano nacional.

A palavra final do PNEDH foi definida através de uma Reunião Exraordinária do CNEDH em Brasília. Para divulgar o texto final, a SEDH lançou a versão 2006 durante o Congresso Iberoamericano de Educação em Direitos Humanos, com a presença das Altas Autoridades dos Direitos Humanos e Países Associados do Mercosul e do presidente Luiz Inácio da Silva.

Durante o período de formulação do PNEDH houve três conferências nacionais de direitos humanos: uma em 2003, outra em 2004 e a outra em 2006.Durante essa fase de formulação estava em vigor o Programa Nacional de Direitos Humanos 2 (2002). Logo, só com o Programa Nacional de Direitos Humanos 3 (2009) é que o PNEDH foi inserido. Bases para uma cultura de Direitos Humanos e a Proteção e Promoção dos Direitos Humanos eram eixos de ação, onde já se definia como ação de médio prazo a realização do Plano de Ação da Década para a Educação em Direitos Humanos (BRASIL, 2006).

Em todos os momentos definidos como estratégicos para a elaboração do PNEDH, como a Consulta Nacional, os Encontros Estaduais de Educação em Direitos Humanos, as Conferências Nacionais, a realização de Seminários e Congressos e as Consultas Públicas no período de 20032006, o CNEDH participou ativamente dos debates relacionados à Educação em Direitos Humanos, tendo um papel decisivo, realizando palestras em seminários e encontros, promovendo audiências públicas, participando dos encontros e vídeo-conferências, acompanhando todo o processo de discussão e fechamento do texto final, prestando o trabalho de assessoramento direto à Secretaria dos Direitos Humanos. O texto final da versão 2006 foi aprovado pelo CNEDH nos dias 9 e 10 de novembro de 2006.

Educação \& Formação, Fortaleza, v. 3, n. 7, p. 137-161, jan./abr. 2018

DOI: http://dx.doi.org/ 


\subsection{0 processo de implementação}

O processo de implementação do PNEDH, de 2004-2015, envolveu inicialmente a criação de uma coordenação geral de Educação em Direitos Humanos junto ao Ministério da Justiça na Secretaria dos Direitos Humanos. Para as duas primeiras coordenações o CNEDH foi consultado com a indicação de nomes para a coordenação executiva.

Para concretizar a implementação do PNEDH, a SEDH realizou um Projeto de Cooperação Técnica com a Unesco, dialogando e pactuando as prioridades com o comitê. De 2004-2007, foram propostos e realizados cinco objetivos estratégicos: Divulgação do Plano Nacional de Educação em Direitos Humanos (PNEDH - versão 2003) para preparar a versão de 2006; Estabelecimento de parcerias, com vistas à realização e apoio a ações de Educação em Direitos Humanos; Formação e capacitação de promotores de direitos humanos; Formulação e divulgação de estudos, pesquisas e produção de materiais relativos à Educação em Direitos Humanos; Monitoramento e avaliação da implementação do PNEDH (BRASIL, 2004).

Para Divulgação do Plano Nacional de Educação em Direitos Humanos (PNEDH - versão 2003), para preparar a versão de 2006, foi apoiada e incentivada a participação de membros do CNEDH em espaços e eventos internacionais, nacionais, regionais e estaduais (Reunião de Altas Autoridades do Mercosul em Direitos Humanos, I Reunión Materiales Didácticos de Derechos Humanos en el Mercosur, Fórum Educacional do Mercosul; Reunião do GT de Educação e Cultura em Direitos Humanos das Altas Autoridades em Direitos Humanos do II Seminário Educação em Direitos Humanos e Cidadania: desafios para a formação do professor. Com a participação de palestrantes internacionais vindos para o Congresso; mesas redondas nos Congressos Brasileiros de Extensão Universitária; Encontros da Associação Nacional de Direitos Humanos; Encontros Nacionais da OAB; Conferências Nacionais e Estaduais de Direitos Humanos; XXII Encontro Nacional do Fórum de Pró-Reitores de Extensão das Universidades Públicas Brasileiras; Congresso Interamericano de Educação em Direitos Humanos no Brasil.

Segundo Rua (2012, p. 34):

As políticas públicas (policies) ocorrem em um ambiente tenso e de alta densidade política (politics), marcado por relações de poder, extremamente problemáticas, entre atores do Estado e da sociedade, entre agências intersetoriais, entre os poderes do Estado, entre o nível nacional e níveis subnacionais, entre comunidade política e burocracia.

Educação \& Formação, Fortaleza, v. 3, n. 7, p. 137-161, jan./abr. 2018

DOI: http://dx.doi.org/

http://seer.uece.br/redufor 
Para o estabelecimento de parcerias, com vistas a implementar e apoiar ações de Educação em Direitos Humanos, foi relevante: o Fórum pela Democratização dos Meios de Comunicação, os Fóruns de Graduação, de pesquisa e pós-graduação e de extensão universitária; Rede Nacional de Cursos de Especialização em Segurança Pública (Renaesp) da Senasp-MJ; o Movimento Nacional de Direitos Humanos; a Rede Brasileira de Educação em Direitos Humanos; a Secretaria de Educação Continuada, Alfabetização e Diversidade, a Secretaria de Ensino Superior, Secretaria de Educação Especial do MEC; a Comissão de Direitos Humanos e Minorias, a Comissão de Educação, o Conselho Nacional de Educação; a Reunião de Altas Autoridades de Direitos Humanos e Países Associados; a Unesco e a OEl; dentre outros.

O CNEDH, apesar de órgão consultivo da SEDH, durante os quatro anos de formulação e seis anos de implementação atuou como órgão de controle e monitoramento:

[...] esse núcleo pode ser bastante abrangente, reunindo decisões sobre diversos aspectos. Quando, ao contrário, são muitos os conflitos, as questões são demasiado complexas ou a decisão requer grande profundidade de conhecimentos, a decisão tende a cobrir um pequeno número de aspectos, já que muitos deles têm as decisões adiadas para o momento da implementação. (RUA, 2012, p. 36).

Para a formação e capacitação de promotores de direitos humanos, foram inseridos como temas em Congressos Brasileiros de Extensão, nas Reuniões do Fórum Nacional de Pró-Reitores de Extensão das Universidades Públicas Brasileiras; nas Oficinas da Matriz Curricular promovida pela Senasp-MJ; Encontro Nacional da Undime, dentre outros; assim como para apoiar a formação realizando lançamento de editais públicos para a realização de Cursos de Extensão em Educação em Direitos Humanos em parceria coma Secad/MEC, para a formação de comitês estaduais de Educação em Direitos Humanos. São realizados anualmente, prêmios nacionais onde a Educação em Direitos Humanos é um dos temas de premiação com vistas a identificar experiências inovadoras e promover o intercâmbio. São incentivados através de projetos apoiados de cursos e seminários em parceria com os Comitês Estaduais de Educação em Direitos Humanos, Instituições de Ensino Superior, Entidades Não Governamentais e Governos Estaduais e Municipais.

A função de monitoramento e avaliação da implementação do PNEDH tem sido acionada pelas reuniões ordinárias do $\mathrm{CNEDH}$, as conferências de direitos humanos e os trabalhos de consultorias. 


\section{QUINZE ANOS DE PNEDH: ASPECTOS CONSTRUTIVOS}

\subsection{Rede institucional}

A criação do CNEDH como órgão consultivo foi relevante para legitimar as ações em face da composição de especialistas, gestores públicos e representantes da sociedade civil. Desse processo, outros estados federados como Bahia e Espírito Santo formalizaram a criação de planos estaduais de Educação em Direitos Humanos.

Com o apoio institucional do Ministério da Justiça e do Ministério da Educação foram criados gerências e coordenações nos Estados, assim como comitês estaduais, recentemente sendo criado o Fórum Nacional de Comitês Estaduais de Educação em Direitos Humanos.

\subsection{Participação social}

Desde a criação da Década da Educação em Direitos Humanos que entidades e movimentos de direitos humanos vêm pautando a criação de fóruns e conferências de modo a construir de forma democrática, planos e programas de ação voltados para a Educação em Direitos Humanos. Têm sido assim com a Consulta Nacional que elaborou o PNEDH assim como com as Conferências Nacionais que refletem e monitoram a atuação do poder público, atualizando a agenda pública.

\subsection{Educação em Direitos Humanos na Educação Superior}

As conquistas no campo da Educação Superior têm sido pautadas pelos fóruns de gestores assim como pelo conjunto de educadores a exemplo da inclusão dos Direitos Humanos no Plano Nacional de Extensão Universitária a criação do Programa Nacional de Extensão, tendo os temas dos direitos humanos e da Educação em Direitos Humanos nos editais PROEXT - MEC, recentemente interrompidos.

Iniciativas da extensão desdobraram-se em disciplinas e cursos de extensão, assim como em cursos de especialização e aperfeiçoamento, e mais recentemente, em cursos de mestrados 
interdisciplinares, criando direitos humanos como parte da área multidisciplinar da Capes. Atualmente, são cerca de treze mestrados interdisciplinares em Direitos Humanos (USP, UFG, UFPE, UFPB, UNB, UNIBAN, entre outras instituições).

\subsection{Normatização nas políticas educacionais}

Um passo relevante para entrada dos direitos humanos na educação formal foi dado pela parceria entre o Conselho Nacional de Educação e a Secretaria dos Direitos Humanos e o Ministério da Educação para criação das Diretrizes Nacionais para a Educação em Direitos Humanos e a inserção da Educação em Direitos Humanos nas Diretrizes do Ensino Médio e nas Diretrizes da Formação Inicial e Continuada de Professores.

No âmbito da diversidade, os direitos humanos numa perspectiva intercultural têm atravessado as diretrizes nacionais voltadas para educação infantil, educação nas prisões, educação indígena, educação étnica, educação de gênero e educação sobre a diversidade sexual, educação quilombola, dentre outras.

\subsection{Educação em Direitos Humanos na Educação Básica}

A inserção da Educação em Direitos Humanos na educação básica teve o apoio institucional da Secretaria de Educação Continuada e Diversidade, quando ao longo do período de 2003-3006 criou programas e projetos de Educação em Direitos Humanos, a exemplo de Ética e Cidadania, Escola que Protege, Mais Educação, Programa Nacional de Extensão Universitárias, Educação para a Diversidade, dentre outros.

A criação da rede de cursos a distância envolvendo universidades públicas, federais e estaduais, ampliou a formação de redes universitárias, como a REDH Brasil e a Rede de Cursos à Distância de Educação em Direitos Humanos, envolvendo cursos à distância de extensão, aperfeiçoamento e especialização com apoio do FNDE e da Capes.

Educação \& Formação, Fortaleza, v. 3, n. 7, p. 137-161, jan./abr. 2018

DOI: http://dx.doi.org/

http://seer.uece.br/redufor 


\subsection{Educação em Direitos Humanos na Segurança Pública}

A Rede de Altos Estudos em Segurança Pública (Renaesp) criou uma rede de cursos de especialização tendo os direitos humanos como conteúdo transversal. Além desta iniciativa, foi criada a Escola de Polícia com cursos a distância disponíveis para as corporações de segurança, assim como os projetos de Formação como as Jornadas em Direitos Humanos.

Um passo relevante foram as Matrizes Nacionais de Formação voltadas para as polícias, as guardas municipais e os agentes penitenciários; inovando os currículos das academias de policiais e escolas do judiciário. Com tais iniciativas, surgiu uma produção bibliográfica relevante sobre direitos humanos e segurança cidadã.

\section{PNEDH, QUINZE ANOS: ASPECTOS CRÍTICOS E DESAFIOS}

A produção de materiais em Educação em Direitos Humanos constitui uma demanda permanente no campo da educação. As iniciativas de formação têm gestado uma produção considerável, embora tal produção tenha limites de alcance, uma vez que não é feita considerando o território nacional. A pluralidade cultural exige uma diversificação da produção didática. Iniciativas de editais não têm sido suficientes para atender a demanda. A descontinuidade dos editais anuais para apoio a projetos de publicações e materiais educativos e de ações não formais é um problema a ser enfrentado.

A rede de formação em Educação em Direitos Humanos envolvendo os diversos níveis e modalidades de educação, assim como os diversos campos das políticas sociais, requer um tempo de amadurecimento e aperfeiçoamento que atenda a demanda nacional e regional.

A criação da área de direitos humanos na Capes como do campo multidisciplinar, foi um passo relevante, entretanto, o estímulo a bolsa de pesquisa e intercâmbio ainda é insuficiente para tender a demanda atual. Com isso, os direitos humanos têm sido pesquisados de forma ampla através da pós-graduação e graduação. Esse mapeamento da produção nacional constitui um campo vasto de pesquisa.

Na extensão, a inclusão da Educação em Direitos Humanos no PROEXT criou alternativas para a Educação em Direitos Humanos em modalidades não formais e formais com diferentes 
públicos em situação de vulnerabilidade social. Entretanto, esse programa não teve continuidade. Contudo, tal ação encontra-se prevista no Programa Nacional de Direitos Humanos 3 (2009).

Um retrocesso ocorreu na aprovação do Plano Nacional de Educação (2014-2024) que foi a retirada das questões de identidade de gênero e diversidade sexual do plano, a partir do fortalecimento de uma conjuntura autoritária e neoliberal.

A abrangência territorial e multiétnica do país demandam a continuidade de projetos e programas de ações em Educação em Direitos Humanos.

Dentre as demandas atuais em direitos humanos no campo educacional, pode-se identificar necessidades, como:

- Criação de uma rede nacional de Comitês Estaduais, Municipais e Nacional de Educação em Direitos Humanos com o fortalecimento de um Fórum Nacional;

- Revisão do PNEDH com quinze anos de criação através de um processo de ampla participação social, dialogando nos Estados e Municípios, Conselhos de Direitos, Conselhos de Políticas Públicas, Conselhos de Educação, Comitês de Educação em Direitos Humanos; Educadores Prisionais, Educadores nas Academias de Policias, IES, Fóruns de Formação de Professores, dentre outros;

- Apoio institucional do poder público aos cursos de extensão, aperfeiçoamento e especialização presenciais e à distância com as IES Públicas;

- Inserção da Educação em Direitos Humanos na formação dos profissionais da comunicação social;

- Diálogo com os Conselhos Estaduais e Municipais de Educação com os Conselhos de Direitos fortalecendo a implementação das Diretrizes Nacionais envolvendo Direitos Humanos e Diversidade Humana;

- Inserção da Educação em Direitos Humanos na Educação em Prisões;

- Fomento à Pesquisa e à área temática e interdisciplinar de Direitos Humanos na Capes;

- Implementação das Diretrizes Nacionais da Educação em Direitos Humanos e das Diretrizes Regionais da Educação em Direitos Humanos do Mercosul;

- Criação de um programa de elaboração de material educativo em direitos humanos;

- Fomento a criação de programas e projetos de formação em Educação em Direitos Humanos voltados para educação superior e a educação básica;

Educação \& Formação, Fortaleza, v. 3, n. 7, p. 137-161, jan./abr. 2018

DOI: http://dx.doi.org/ 
- Promoção do intercâmbio de experiências de Educação em Direitos Humanos no âmbito do Mercosul e países associados;

- Diálogo entre gestores da educação, associações do campo da educação e o CNEDH para a criação de estratégias de educação em e para os direitos humanos;

- Ampliação do CNEDH num Conselho Nacional de Educação e Cultura de Direitos Humanos;

- Ampliar a representação dos segmentos sociais e profissionais nas ações do CNEDH de modo a promover uma articulação nacional profícua.

Esperamos ter contribuído com uma reflexão acerca dos quinze anos do PNEDH.

\section{REFERÊNCIAS}

ADORNO, T. W. Educação e emancipação. 3. ed. São Paulo: Paz e Terra, 2003.

ARTAL, C. U. Las Naciones Unidas y la Educación en Derechos Humanos. Pamplona: Eunsa, 2004.

BENEVIDES, M. V. Educação, democracia e direitos humanos. Jornal da Rede, n. 1, p. 12, 1997.

BETO, F. Educação em Direitos Humanos. In: ALENCAR, C. (Org.). Direitos mais humanos. Rio de Janeiro: Garamound, 1998. p. 45-54.

BRASIL. Comitê Nacional de Educação em Direitos Humanos. Plano Nacional de Educação em Direitos Humanos. Brasília, DF: Secretaria Especial dos Direitos Humanos da Presidência da República, 2007.

BRASIL. Constituição de 1988. Constituição da República Federativa do Brasil. Diário Oficial [da] República Federativa do Brasil, Poder Executivo, Brasília, DF, 5 out. 1988.

BRASIL. Lei no 9.394, de 20 de dezembro de 1996. Estabelece as Diretrizes e Bases da Educação Nacional. Diário Oficial [da] República Federativa do Brasil, Poder Executivo, Brasília, DF, 21 dez. 1996.

BRASIL. Portaria Federal no 98, de 09 de julho de 2003. Institui o Comitê Nacional de Educação em Direitos Humanos. Diário Oficial [da] República Federativa do Brasil, Poder Executivo, Brasília, DF, 10 jul. 2003.

BRASIL. Programa Nacional de Direitos Humanos. Brasília, DF: Ministério da Justiça, 1996.

Educação \& Formação, Fortaleza, v. 3, n. 7, p. 137-161, jan./abr. 2018

DOI: http://dx.doi.org/

http://seer.uece.br/redufor 
BRASIL. Relatório de Progresso. 2004-2005. Projeto Educação em Direitos Humanos: construindo uma cultura de respeito à democracia e a justiça. Brasília, DF: Secretaria Especial dos Direitos Humanos da Presidência da República, 2005.

FUNDO DAS NAÇÕES UNIDAS PARA A INFÂNCIA (UNICEF). Convenção sobre os direitos da criança. 1989. Disponível em: <http://www.unicef.org.br/>. Acesso em: 26 jan. 2018.

GOHN, M. G. História dos movimentos e lutas sociais: a construção da cidadania dos brasileiros. São Paulo: Loyola, 1995.

IGLESIAS, E. V. O papel do Estado e os paradigmas econômicos na América Latina. Revista de la Cepal, Santiago, n. 100, p. 45-53, 2010.

MAGENDZO, A. Educación en derechos humanos: un desafío para los docentes de hoy. Santiago: LOM, 2006.

NOVAMÉRICA. Projetos sociais: como elaborar? São Paulo: Paulinas, 1998.

ORGANIZAÇÃO DAS NAÇÕES UNIDAS (ONU). Diretrizes para a formulação de planos nacionais de ação para a Educação em Direitos Humanos. Quinquagésima Segunda Sessão da Assembleia Geral, 20 de outubro de 1997.

ORGANIZAÇÃO DOS ESTADOS AMERICANOS (OEA). Resoluções da OEA. Disponível em: <http://www.oas.org/consejo/pr/ag/resdecs45.asp>. Acesso em: 15 jun. 2015.

OEA. Cuadragésimo primer período ordinario de sesiones. Actas y Documentos, San Salvador, v. 1, p. 236-238, 2011.

OEA. Cuadragésimo segundo período ordinário. Actas e Documentos, Cochabamba, v. 1, p. 147151, 2012.

RUA, M. G. Políticas públicas. 2. ed. Florianópolis: UFSC, 2012.

SILVA, H. P. Educação em Direitos Humanos: conceitos, valores e hábitos. 1995. Dissertação (Mestrado em Educação) - Programa de Pós-Graduação em Educação, Universidade de São Paulo, São Paulo, 1995.

VILHENA, O. V. (Org.). Direitos humanos: normativa internacional. São Paulo: Max Limonad, 2001.

VIOLA, S. E. A. Direitos humanos e democracia no Brasil. São Leopoldo: Unisinos, 2008.

ZENAIDE, M. N. T. A linha do tempo da Educação em Direitos Humanos na América Latina. In: RODINO, A. M. et al. (Org.). Cultura e Educação em Direitos Humanos na América Latina. João Pessoa: UFPB, 2014. p. 29-60.

Educação \& Formação, Fortaleza, v. 3, n. 7, p. 137-161, jan./abr. 2018

DOI: http://dx.doi.org/

http://seer.uece.br/redufor 
ZENAIDE, M. N. T. Educação popular e Educação em Direitos Humanos: aproximações, diálogos e contribuições teórico-práticas. In: SANTORO, E.; BATISTA, G. B. M.; ZENAIDE, M. N. T. (Org.). Direitos humanos em uma época de insegurança. Porto Alegre: Tomo, 2010a. p. 355-374.

ZENAIDE, M. N. T. Políticas de extensão universitária e a disputa pela hegemonia: a questão dos direitos humanos na UFPB. João Pessoa: UFPB, 2010b.

Recebido em 29 de setembro de 2017.

Aceito em 8 de fevereiro de 2018. 